\title{
Competency-based Feedback for the Improvement of Employment Outcomes for Computing Students
}

\author{
Dominic Palmer-Brown \\ Life Sciences \& Computing \\ London Metropolitan University \\ United Kingdom \\ d.palmer-brown@londonmet.ac.uk
}

\author{
Fang Fang Cai \\ Science \& Technology \\ Anglia RuskinUniversity \\ United Kingdom \\ fangfangcai@anglia.ac.uk
}

\author{
Preeti Patel \\ Life Sciences \& Computing \\ London Metropolitan University \\ United Kingdom \\ p.patel@londmet.ac.uk
}

\begin{abstract}
Much of modern education is steeped in the acquisition of skills that will strengthen the employability prospects of learners. The concept of work-readiness has come to mean framing the academic curriculum with as many opportunities for gaining the experience of work as possible and thereby developing those professional skills that industry demands of new Computing graduates. This has led to, among other provisions, the embedding of work-related, work-based and project-based components into the academic curriculum for which newer forms of assessment and feedback are necessary.

This paper reports on a study conducted with a cohort of Computing students whose degree includes an embedded final year work-related learning (WRL) module. Findings from a previous pilot study highlighted the severe lack of awareness and understanding on the part of students for competency building. In order to tackle this deficiency, this current work employs an adapted competency framework, developmental feedback and self-evaluation tools for direct use on the work-related learning module. This powerful combination of tools results in significant improvement in students' perceptions regarding their competencies with overall module performance also increasing significantly. More importantly, it has been possible, through cluster analysis and dimension reduction, to optimise the competency framework to a condensed form which can be readily utilised throughout the work experience.
\end{abstract}

Keywords—competency, graduate skills, employability

\section{INTRODUCTION}

The past decade has seen the fortifying of employability skills acquisition into Higher Education (HE) programmes in all subject disciplines. On the one hand, the priority placed by students on developing generic, transferable and work-related skills as an integral part of their academic study in order to enhance their employment prospects has never been higher. On the other hand, employers continue voicing their strong concerns over graduates who are lacking necessary problem- solving, business communication and team-working skills required in the workplace. These dual demands have been responded to by the HE sector with the introduction and embedding of several work-related learning initiatives into the academic curriculum [1], [2].

Work-related learning initiatives are particularly predominant in the computing, science and business disciplines where most take the form of a module with a work placement opportunity and a series of assessments [3], [4] and [5].

We focus here on our experience of delivering workrelated learning to Computing students, who typically engage well with the technical aspects of software development projects, but do not necessarily know how to practice workplace skills. In order to foster a deeper appreciation of competency building, a simplified competency framework which can be used alongside a set of developmental feedback cues for self-evaluation purposes has been designed for use by students on work-related learning projects.

In this paper we firstly present a detailed background encompassing the three strands of competency frameworks, developmental feedback and self-evaluation which underpin our study. In section III we present the intervention strategy deployed to Computing students. In section IV we report on the effect that this intervention has had on students and discuss the implications for the improvement of employment outcomes. Section V provides some concluding remarks.

\section{BACKGROUND}

\section{A. Competency Frameworks}

The concept of 'competency' has materialised outside the higher education system to characterise an individual's set of skills and proficiencies that are relevant to employability. The language of competency is heavily utilised by employers when considering staff selection, appraisal, continued professional development, technical training and development. However, students and new graduates are not proficient in this language and therefore face challenges when entering the employment market. 
Within academia, competency frameworks have been developed, of particular note for software engineers [6], [7], [8]. However, it is within the professional and employment arenas that competency frameworks are most common, and particularly prolific in science, medicine, engineering, computing and IT, where they are often aligned to continuing professional development and certification. Examples of professional competency frameworks readily available for the various professions of Information Technology, Cybersecurity and Information Management are the SFIA, NICE and IISP frameworks respectively.

These three professional competency frameworks all share the particular common theme of systematically itemising, at varying degrees of detail, the entire breadth of skills and knowledge that a practicing professional is required to exhibit. However, this results in frameworks that are huge and unwieldy for the purposes of developing students within an academic programme. Although SFIA does include a levelling of expertise (from level 1 to 7 ) where an entry-level professional could be a new graduate and therefore deemed to be at level 1, the detail with which the skills are represented would make them unusable by a novice. In addition, it is clear that the frameworks adhere to their own specific terminology; for example, NICE KSAs can be interpreted as competencies in SFIA. This again means that the use of the framework for personal development can be a daunting prospect to a novice.

Professional frameworks have goals that are beyond just personal development - they enable an organisation to standardise skills for performance measurement, for reward schemes, for recruitment, for targeted training and for organisational efficiency and productivity. In addition, professional frameworks are very commonly aligned to industry certification and therefore fulfil an entirely different need. For these reasons, there is a need to arrive at a competency framework which can be readily utilised within an academic programme in the context of a work-related learning platform.

\section{B. Developmental Feedback}

Developmental feedback is very different from evaluative feedback as it looks forward to actions for improvement. Specifically, developmental feedback is not considered at the conclusion of an exercise, rather it is continual and formative. Developmental feedback can empower students because it can help them to identify weaknesses or gaps and can reinforce their role in enabling positive changes. Whilst the term developmental feedback has been chiefly confined to the corporate environment, the term feed forward has become significant in the initiatives deployed to engage students further with their learning.

Feed forward can be seen as being the reverse of feedback where a normal cause-effect relationship can be turned upsidedown. A feed forward occurs when an understanding of the current deficiency is fed into an experience leading to improvement in the future. Educators have developed various interventions to aid the feed forward process; examples include the use of high impact written feedback from one assignment to the next [9], a series of interventions which begin with engaging students with the criteria to be used for assessment [10], several submissions of a report on a researchled module where students have access to their own and their peers' feedback on draft submissions [11]. Other examples, such as [12] utilise the feed forward concept at a module-level in a more generic way to promote course level and subjectspecific outcomes.

\section{C. 'Self' Skills}

A general premise of HE study is that students are able to build their 'self' skills and so be able to self-evaluate, selfappraise, self-reflect, self-manage and self-regulate. As many students find this challenging, the more opportunities for practice within their degree programme the better. Selfevaluation together with peer or tutor feedback can assist in life-long learning and effectiveness in the workplace. Examples include [13] who highlight the need for both a selfregulation and a self level in their model of feedback to enhance learning and [14] for an internet tool for selfevaluation purposes with which students can take control of their own self-directed learning.

\section{TOOLS}

A competency framework (CFWRL) designed to be used by and for students on a work-related learning module was developed with the two specific aims that:

1. It must allow for the support and dispensing of developmental feedback.

2. It must be usable by students for self-evaluation and selfregulation purposes.

The framework has drawn heavily from the NICE framework in terms of the separation of competencies into the associated sections: Personal Effectiveness competencies, Academic competencies and Workplace competencies. However, whereas NICE views these as tiers (that are presumably developed by individuals over time), in CFWRL we take the view that students on a work-related learning module develop their academic and workplace competencies in parallel and that furthermore, personal effectiveness competencies are developed in all areas of a student's environment. Within the NICE framework, an additional two tiers, namely 4 and 5 are related to industry-wide technical competencies and industry-sector functional areas respectively; these are not included in CFWRL but a generic category of job role competencies is included for those projects which may need them. Fig. 1 depicts the three main categories contained within CFWRL and the competencies included in each category. The competencies incorporated here are the most widely used across all the professional frameworks but have been assimilated and labelled in a customised way for optimum use by students and academic tutors. The total number of competencies has been limited to twenty as anything more may have an adverse effect on student engagement. 
The CFWRL framework is then utilised to create a set of developmental feedback cues which can be used in a selfregulating manner under the guidance of a tutor. Fig. 2. gives the competency form created to allow students to self-rate themselves on each of the 20 competencies. The manner in which this form was deployed is detailed in the next section, but essentially students completed this form at the commencement and at the conclusion of their WRL experience. The ratings themselves were the subject of developmental feedback sessions and formed the basis on which students explored the corresponding feedback for those competencies that needed improvement.

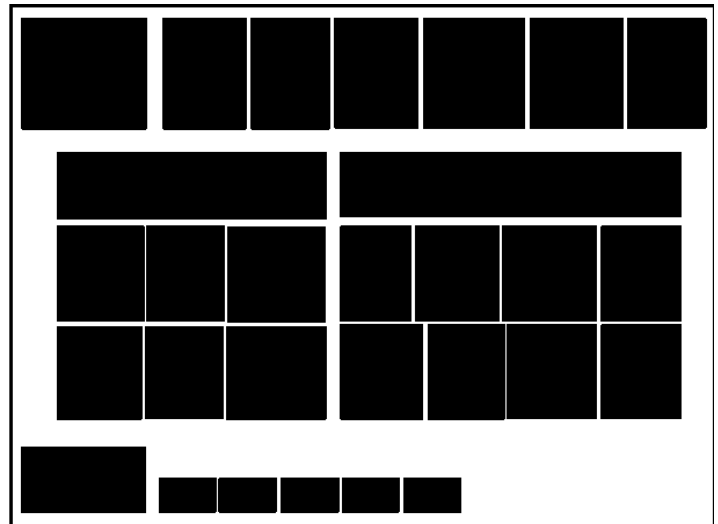

Figure 1. Competency Framework for Work-Related Learning

In terms of building the bank of developmental feedback cues, care was taken to use terminology which students could understand and utilise for improvement whilst still reflecting professional terminology. Figure 3 depicts an example of the developmental feedback cues created for just one of the 20 competencies, namely "Planning, organisation and prioritising". The entire set of feedback cues for all 20 competencies were constructed within an interactive webpage for ease of use and search. The use of these three elements of the intervention are depicted in the student journey diagram shown in Fig. 4.

A purposive sampling of participants was used to include students following a Computing degree in which the majority of the sample had undertaken a work-related learning (WRL) module. 102 such students were initially identified with another 30 students constituting a control group. The universally employed Likert scale was used to measure the level of skill as perceived by individual students for the 20 competencies in the model. The decision to use a 7-point scale was taken as competence is seldom a straightforward question of 'can or cannot'; rather it is useful to allow a student to evaluate each competency at a broader range of skill level.

\begin{tabular}{|c|c|}
\hline Module: & Your name: \\
\hline Skill & Please circle for each competency: \\
\hline & 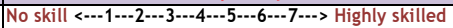 \\
\hline \multicolumn{2}{|l|}{ Workplace competencies } \\
\hline Teamwork and relationship building & $\langle--1234567---\rangle$ \\
\hline Creative and innovative thinking & <---1 233456 7---> \\
\hline Decision making and judgement & $\langle--12344567---\rangle$ \\
\hline Planning, organisation and prioritising & $\langle---12344564$--.> \\
\hline Business fundamentals/commercial awareness & $\langle--123345667---\rangle$ \\
\hline Working with tools and technology & $\langle---12344564--\cdot\rangle$ \\
\hline Problem-solvingandresearchinginformation & <---1 2344567 ---> \\
\hline Customer focus / orientation & <---12234456 7---> \\
\hline \multicolumn{2}{|l|}{ Personal effectiveness competencies } \\
\hline Drive, initiative and results focus & <---1 23344567 ---> \\
\hline Adaptability and flexibility & $\langle---122344564$---> \\
\hline Self-management and self-motivation & $\langle--12334567$---> \\
\hline Professionalism & $\langle--123345667--\rangle$ \\
\hline Interpersonal effectiveness & $\langle--123345667--\cdot\rangle$ \\
\hline Integrity and reliability & $\langle---12334567--\rangle$ \\
\hline \multicolumn{2}{|l|}{ Academic competencies } \\
\hline Reading/writing & <---1 $23345647--\rangle$ \\
\hline Listening/speaking & $\langle--12344567---\rangle$ \\
\hline Mathematics & <---1233456 7---> \\
\hline Critical and Analytic thinking & <---1 2344567 ---> \\
\hline Fundamental IT skills & <---1233456 7---> \\
\hline Study skills & <---123345 67 ---> \\
\hline
\end{tabular}

Figure 2. Student Competency Self-rating Form

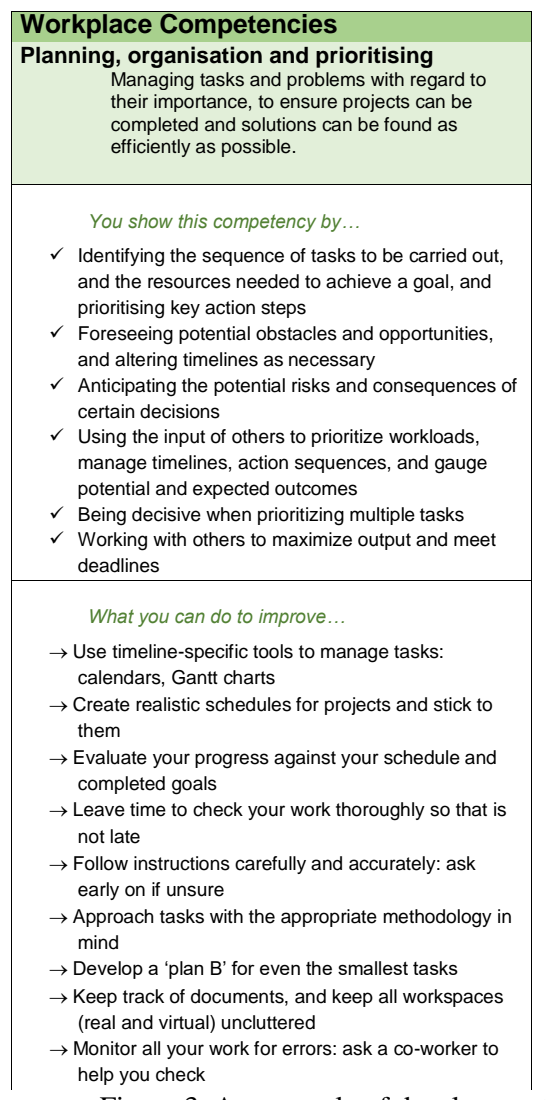

Figure 3. An example of developmental cues 
The advantage of simplicity of use was deemed to outweigh the disadvantage of individuals' avoidance of choosing at the extremes of the scale. The self-evaluative survey shown in Fig. 2 was administered to all students at the beginning and also at the end of their WRL experience. The control group were also treated in the same way in that they were asked to complete the survey at the beginning and end of the semester. Students were required to provide a rating of their chosen skill level from 1 (no skill) to 7 (highly skilled).

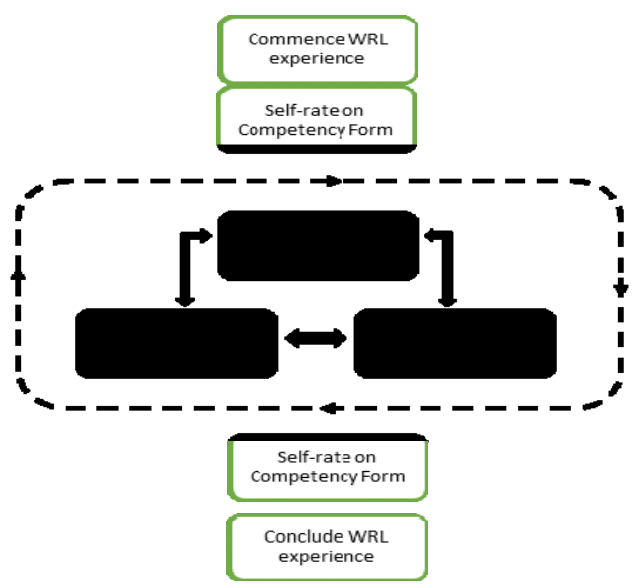

Figure 4. Students' Work-Related Learning Journey

All students were asked to respond to the survey at approximately the same time prior to the start of the bulk of their WRL experience. Students were requested to include their names on the response and to answer as honestly as possible. An anonymised online survey facility was not used as each individual had to be identified in order to participate in the developmental feedback. The sample was then randomly divided into two, with one half of the group to be given developmental feedback during the course of 6-8 weeks. Wherever possible the feedback was given face-to-face, but on occasion these sessions were conducted by telephone or videochat. Some students had more than one feedback session but no student had more than three. An interactive webpage was created to allow students to focus on particular competencies at a time. The feedback sessions were based around the use of this webpage as well as discussions on competence improvement for current work tasks.

\section{RESULTS ANDDISCUSSION}

\section{A. Results of Students' Self-rating}

We compared the differences in students' self-assessed competencies at the start and end of their semester (or year) for all students in the sample. We conducted four independent 2 sample t-tests on the basis of whether students have taken a
WRL module or not and also on the basis of whether they had received developmental feedback or not.

Test 1: comparing the difference in competence score totalled over all 20 competencies for those students who had studied the WRL module but received no developmental feedback. The total after score was not significantly greater than the total before score ( $\mathrm{p}=0.07$ using a 1 -sided test).

Test 2: comparing the difference in competence score totalled over all 20 competencies for those WRL students who had received developmental feedback. The total after score for this group of students was significantly greater than the total before score ( $\mathrm{p}=0.00002$ using a 1 -sided test).

Similarly, for those students who had not taken the WRL module, we carried out a 1-sided test of whether the total score of all competencies was greater at the end of the semester (or year) than at the start, separately considering receipt of feedback.

Test 3: comparing the difference in competence score totalled over all 20 competencies for those students who had not studied the WRL module and received no developmental feedback, there was not a strong significant greater score $(p=0.03)$ at the end of the semester (or year) than at the beginning.

Test 4: comparing the difference in competence score totalled over all 20 competencies for those students who had not studied the WRL module and who had received developmental feedback, there was no significant difference $(p=0.11)$ between scores at the start and end of the semester (or year).

\begin{tabular}{|c|c|c|c|c|}
\hline & & $\begin{array}{l}\overline{\mathrm{x}}_{\mathrm{b}} \\
\text { before } \\
\text { score }\end{array}$ & $\begin{array}{c}\overline{\bar{z}}_{\mathrm{a}} \\
\text { after } \\
\text { score }\end{array}$ & $\begin{array}{c}\mathrm{p} \text {-value } \\
\text { for } \\
\text { difference }\end{array}$ \\
\hline \multirow[t]{2}{*}{$\begin{array}{c}\text { WRL } \\
\text { students }\end{array}$} & $\begin{array}{c}\text { no } \\
\text { developmental } \\
\text { feedback }\end{array}$ & $99.5(17.2)$ & $\begin{array}{l}105.0 \\
(19.1)\end{array}$ & 0.07 \\
\hline & $\begin{array}{c}\text { developmental } \\
\text { feedback }\end{array}$ & 97.7 (12.5) & $\begin{array}{l}109.1 \\
(13.5)\end{array}$ & 0.00002 \\
\hline \multirow[t]{2}{*}{$\begin{array}{c}\text { Non } \\
\text { WRL } \\
\text { students }\end{array}$} & $\begin{array}{c}\text { no } \\
\text { developmental } \\
\text { feedback }\end{array}$ & $94.7(8.0)$ & $\begin{array}{l}100.2 \\
(7.0)\end{array}$ & 0.03 \\
\hline & $\begin{array}{c}\text { developmental } \\
\text { feedback }\end{array}$ & $96.5(9.4)$ & $101.2(9.2)$ & 0.11 \\
\hline
\end{tabular}

Next, having noted the apparent variations in the total before and after competencies, we then carried out significance tests using the differences between before and after total scores. In other words, we now included all (i.e. those who had taken a WRL module and those who had not) students and we tested the difference between the before and after scores by taking the difference between the total of the 
20 self-evaluations for those who had and had not received developmental feedback, i.e. we considered $\bar{x}_{\mathrm{a}}-\bar{x}_{\mathrm{b}}$ for those who had or had not received developmental feedback. We tested the following null and alternative hypotheses:

$\mathrm{H}_{0}$ : feedback $(\overline{\bar{x}}-\mathrm{b}) \bar{z}=$ no-feedback $\left(\mathrm{a} \overline{\bar{F}}_{\mathrm{b}}\right) \overline{\bar{w}}$

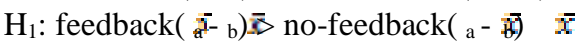

In the case of WRL students, we found a highly significant difference in $\left(\bar{x}_{\mathrm{a}}-\overline{\text {. }}\right.$ ) for those who had received development feedback than for those who had not received any feedback. $(p=0.00005)$. However for those students who did not undertake a WRL module, there is no significant difference in $(\bar{z}-\mathrm{b}) \overrightarrow{\mathrm{m} f}$ they had received the feedback or not. $(\mathrm{p}=0.32)$.

Finally, we progress to testing each of the 20 competencies separately. As we are considering many tests on the same individuals, some form of correction in significance level is advisory. Here we use the Bonferroni correction, which means that with 20 competencies we should use a p-value of $0.05 / 20$ $=0.0025$.

For example, considering Competence 1 (Teamwork and relationship building) for students who had studied the WRL module, we tested the difference between a student's selfevaluation before and after receiving developmental feedback by considering the following hypothesis test:

$\mathrm{H}_{0}$ : feedback(after_Comp1 - before_Comp1) = no-feedback(after_Comp1 before_Comp1)

$\mathrm{H}_{1}$ : feedback(after_Comp1 - before_Comp1) > no-feedback (after_Comp1 before_Comp1)

Table 2. Summary of Competency Tests

\begin{tabular}{|c|c|c|c|c|c|}
\hline \multirow[b]{2}{*}{ Competencies } & \multicolumn{2}{|l|}{ WRL } & \multicolumn{3}{|c|}{ Non-WRL } \\
\hline & $\left(\overline{\mathrm{X}}_{\mathrm{a}}-\right.$ & $\begin{array}{l}1 \text { sided } \\
\mathrm{p} \text {-value }\end{array}$ & $\left(\overline{\mathrm{X}}_{\mathrm{a}}-\right.$ & \multicolumn{2}{|c|}{$\begin{array}{l}1 \text { sided } \\
\mathrm{p} \text {-value }\end{array}$} \\
\hline \multicolumn{6}{|l|}{ Workplace Competencies } \\
\hline Teamwork and relationship building & 0.31 & $0.026 \quad *$ & 0.34 & 0.1545 & $\mathrm{~ns}$ \\
\hline Creative and innovative thinking & 0.58 & $0.00003 \star *$ & 0.49 & 0.0504 & ns \\
\hline Decision making and judgement & 0.13 & $0.16 \quad \mathrm{~ns}$ & 0 & 0.5 & $\mathrm{~ns}$ \\
\hline Planning, organisation and prioritising & 0.74 & $0.00001 \star \star$ & 0.17 & 0.2975 & $\mathrm{~ns}$ \\
\hline $\begin{array}{l}\text { Business fundamentals/commercial } \\
\text { awareness }\end{array}$ & 0.63 & $0.0003 * \star$ & 0.057 & 0.3226 & ns \\
\hline Working with tools and technology & 0.42 & $0.001 \quad \star \star$ & 0.036 & 0.4375 & ns \\
\hline $\begin{array}{l}\text { Problem-solving and researching } \\
\text { information }\end{array}$ & 0.27 & 0.01 & 0.0051 & 0.4909 & ns \\
\hline Customer focus / orientation & 0.79 & $0.00001^{\star \star}$ & 0.16 & 0.1155 & ns \\
\hline \multicolumn{6}{|l|}{$\begin{array}{l}\text { Personal Effectiveness } \\
\text { competencies }\end{array}$} \\
\hline Drive, initiative and results focus & 0.13 & 0.12 & 0.27 & 0.2142 & $\mathrm{~ns}$ \\
\hline Adaptability and flexibility & 0.13 & $0.11 \quad \mathrm{~ns}$ & 0.18 & 0.1853 & $\mathrm{~ns}$ \\
\hline Self-management and self-motivation & 0.64 & $0.0001^{\star \star}$ & 0.067 & 0.4309 & $\mathrm{~ns}$ \\
\hline Professionalism & 0.58 & $0.0004^{* \star}$ & 0.097 & 0.2600 & ns \\
\hline Interpersonal effectiveness & 0.33 & $0.02 \mathrm{~ns}$ & 0.66 & 0.0116 & $\mathrm{~ns}$ \\
\hline Integrity and reliability & 0.42 & $0.00006^{\star \star}$ & 0.25 & 0.1436 & $\mathrm{~ns}$ \\
\hline \multicolumn{6}{|l|}{ Academic competencies } \\
\hline Reading/writing & -0.02 & 0.61 & 0 & & \\
\hline Listening/speaking & -0.02 & 0.61 & 0 & & \\
\hline Mathematics & -0.06 & 0.91 & 0.077 & 0.1456 & $\mathrm{~ns}$ \\
\hline Critical and Analytic thinking & 0.17 & 0.05 & 0.11 & 0.2647 & $\mathrm{~ns}$ \\
\hline Fundamental IT skills & 0.02 & 0.71 & 0 & & \\
\hline Study skills & 0.02 & 0.40 & 0 & & ns \\
\hline
\end{tabular}

ns not significant

$* \quad \mathrm{p}<0.05$

$* * \quad \mathrm{p}<0.0025$
In this case we obtained a (one-sided) p-value of 0.026 , indicating no strong evidence of a difference before and after feedback. Table 2 shows the results of the corresponding tests for all 20 competencies, where the WRL and non-WRL groups are shown separately.

For those students who had experienced WRL, it is noticeable that there is significant difference in virtually all the Workplace and Personal Effectiveness competencies before and after developmental feedback. Also noticeable is that is that those who had not undertaken WRL there was no significant difference regardless of whether there had been development feedback or not.

\section{B. Exploring the competency framework}

We carried out further investigation into the competency framework to consider how competencies are connected to each other. Our aim was to segment and potentially (re)categorise the competencies so that student experience initiatives could be better targeted. To this end we used a dimensionality reduction process to reduce the highly correlated student responses to the 20 competencies. We also made use of cluster analysis and correlation analysis techniques to focus the investigation on the relationships between variables. One aspect of this analysis is reported where we generated dendograms to visualise the distance level at which there are combinations of clusters for the 'before' (Fig. 5) and 'after' (Fig. 6) scoring by students. Considering the dendogram from left to right, with the 20 'before' competencies labelled in abbreviated form on the y-axis, Fig. 5 shows that there are indeed strong groupings of variables. Of particular note is that the personal effectiveness competencies of 'professionalism', 'self-management and self-motivation', and 'interpersonal effectiveness' appear to be more aligned to workplace competencies. Also of note is that 'critical and analytic thinking' and 'mathematics' competencies elicit responses somewhat unlike the other Academic competencies.

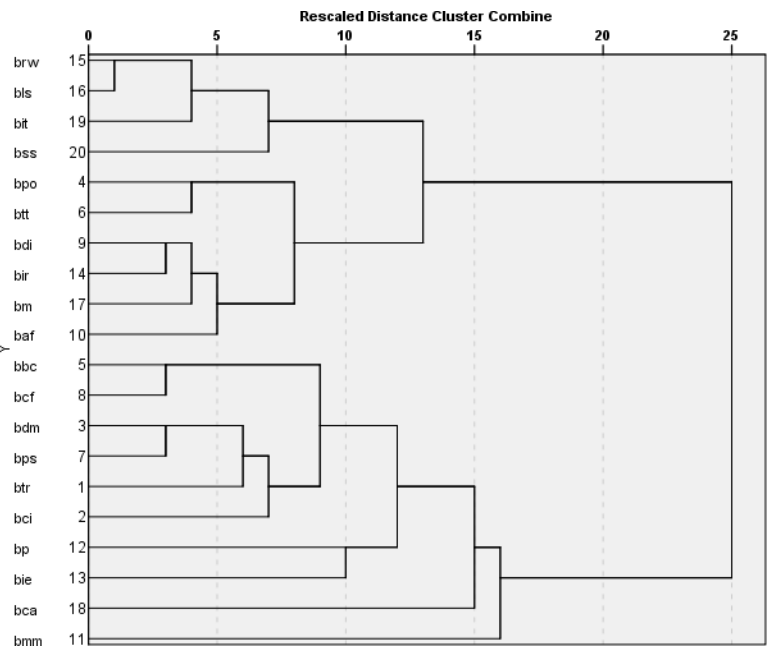

Figure 5. Dendogram of 'before' Competencies 
In contrast to the responses before taking the module, it is interesting to note the dendogram (Fig. 6), where the 20 'after' competencies are labelled in abbreviated form on the y-axis, the cluster analysis of competency scores after taking the module, and where the closeness of the variables differs in the light of their experience. It would appear that students differentiated more between some the competencies after taking the module, indicating that they had better understood the differences between the competencies.

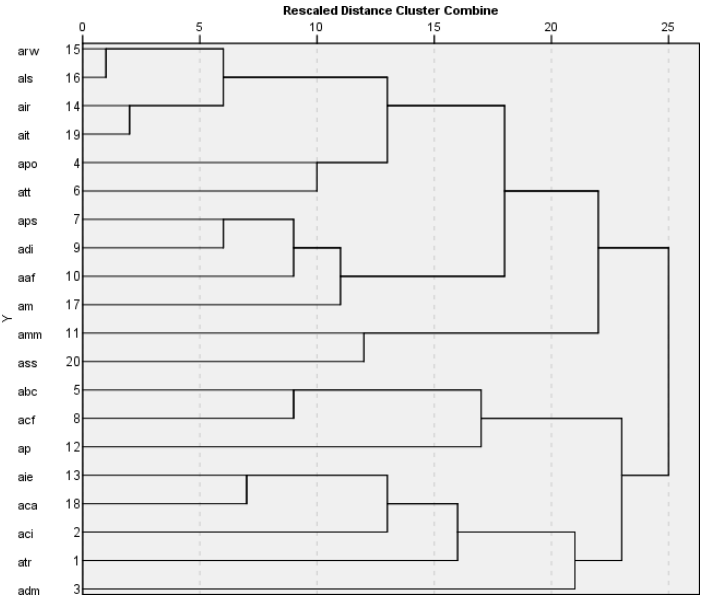

Figure 6. Dendogram of 'after' Competencies

The clustering dendograms illustrate the way students regard the relationships between the various competencies. Their perceptions appear to be quite stable before and after the completion of work related learning. Overall, their selfassessments fall into two broad groupings: Academic and Workplace, with the Personal Effectiveness competencies straddling both Academic and Workplace groups. This suggests that the competency framework is meaningful.

However, two competencies, Self-management and Problem Solving, were converted from the Workplace to the Academic grouping as a result of the work related learning experience and assessment. Though this shift is not surprising in itself, since Self-management and Problem Solving are relevant to both study and work environments, it does serve to distil the Workplace set of competencies, reducing their number by $20 \%$. The result is a tighter Workplace category centering on business acumen and interpersonal skills. Thus, the students appear to have sharpened their perception of the needs of the workplace as a result of their experience, feedback and selfevaluation.

\section{CONCLUSIONS}

The results of the analyses substantiate the original three groupings of competencies, namely Workplace, Personal Effectiveness and Academic. However, there is scope to reconfigure the framework to highlight some of the competencies, leading to a more compact version with which students could work effectively, whilst still potentially making improvements on all 20 competencies. Analysis has shown that there are a handful of skills that stand apart from the 3 main categories and also from each other. These appear to be the competencies that many students would struggle to understand, practice and evidence. Developmental feedback in these areas could prove to be particularly beneficial, as it is during the course of the WRL experience that students may be able grapple with them in some grounded context. Consideration of the scores after taking the WRL module would seem to indicate that students have better understood the competency concepts than before taking it. Thus, we might conclude that we have a means of helping students to refine and develop their understanding of these competencies.

\section{REFERENCES}

[1] Venables, A., \& Tan, G. (2009). Realizing Learning in the Workplace in an Undergraduate IT Program. Journal of Information Technology Education, 8, IIP-17.

[2] Simons, P. R.-J., \& Ruijters, M. C. P. (2008). Varieties of work related learning. Organisational and Personal Contributions to Workplace Learning Environments, 47(4), 241-251. doi:10.1016/j.ijer.2008.07.001

[3] Clements, M. D., \& Cord, B. A. (2013). Assessment Guiding Learning: Developing Graduate Qualities in an Experiential Learning Programme. Assessment \& Evaluation in Higher Education, 38(1), 114-124.

[4] McKinnon, S., \& McCrae, J. (2012). Closing the Gap: Preparing Computing Students for Employment through Embedding WorkRelated Learning in the Taught Curriculum. Industry and Higher Education, 26(4), 315-320.

[5] Jollands, M., Jolly, L., \& Molyneaux, T. (2012). Project-based learning as a contributing factor to graduates' work readiness. European Journal of Engineering Education, 37(3), 143-154.

[6] Rivera-Ibarra, J.G., Rodriguez-Jacobo, J., Serrano-Vargas, M.A., 2010 Competency Framework for Software Engineers. Software Engineering Education and Training (CSEE\&T), 2010 23rd IEEE Conference on 33-40.

[7] Ducrot, J., Shankararaman, V., 2014. Measuring student performance and providing feedback using Competency Framework. Engineering Education (ICEED), 2014 IEEE 6th Conference on 55-60.

[8] Sedelmaier, Y., Landes, D., 2014. A multi-perspective framework for evaluating software engineering education by assessing students' competencies: SECAT — A software engineering competency assessment tool. Frontiers in Education Conference (FIE), 2014 IEEE $1-8$.

[9] Vardi, I. (2013). Effectively Feeding Forward from One Written Assessment Task to the Next. Assessment \& Evaluation in Higher Education, 38(5), 599-610.

[10] Walker, S., \& Hobson, J. (2014). Interventions in Teaching First-Year Law: Feeding Forward to Improve Learning Outcomes. Assessment \& Evaluation in Higher Education, 39(3), 326-338.

[11] Morrell, L. J. (2014). Use of Feed-Forward Mechanisms in a Novel Research-Led Module. Bioscience Education, 22(1), 70-81.

[12] Hughes, G., Wood, E., \& Kitagawa, K. (2014). Use of Self-Referential (Ipsative) Feedback to Motivate and Guide Distance Learners. Open Learning, 29(1), 31-44.

[13] Hattie, J., \& Timperley, H. (2007). The Power of Feedback. Review of Educational Research, 77, 1, 81-112.

[14] Theunissen, N., \& Stubbe, H. (2014), iSELF: The Development of an Internet-Tool for Self-Evaluation and Learner Feedback. Electronic Journal of E-Learning, 12, 4, 313-325. 